\title{
IMPLEMENTING ENERGY CONSERVATION MEASURES: A CASE STUDY ON RETROFITTING A COMMERCIAL BUILDING IN SOUTH AFRICA
}

\author{
AMINA ISMAIL \& FREDDIE INAMBAO
}

Department of Mechanical Engineering, University of KwaZulu-Natal, Durban, South Africa

\begin{abstract}
Energy efficiency is driven by global climate change concerns and the need to reduce carbon emissions and increase sustainability of the built environment. Currently, South Africa is facing an electricity crisis and alternate solutions to energy consumption of state-owned buildings should be explored. This study aimed to conduct a quantitative analysis of the energy savings after retrofitting and implementing ECMs in a state-owned commercial building to determine the electrical energy savings, the effectiveness of energy efficient retrofits, and the correlated cost implications. It was found that ECM retrofits saved an average of $398431 \mathrm{kWh}$ of electrical energy per month amounting to a $67 \%$ improvement in energy efficiency. The total financial savings achieved was R1 902301.26 per year. Barriers to energy efficiency were identified. Lack of funding, resources and knowledge were the most prevalent barriers.

KEYWORDS: Energy Efficiency, Climate change, Energy conservation measures, Barriers
\end{abstract}

Received: Apr 02 2021; Accepted: Apr 22, 2021; Published: Jul 14, 2021; Paper Id.: IJMPERDAUG202122

\section{INTRODUCTION}

Energy efficiency, a popular subject matter, is driven by global climate change concerns and the need to reduce carbon emissions and increase sustainability of the built environment. Numerous research articles highlight the benefits of implementing energy efficiency and sustainability in buildings, including implementation of regulations that encourage new buildings to be designed and built with sustainability energy conservation in mind [1], [2], [3], [4], [5], [6].

Since 2008, the main electricity service provider in South Africa, Eskom, has had challenges with the various electricity plants, causing periodic load shedding and an increase in electricity rates. Considering the utility service provider challenges and high capital costs for new installations, retrofitting is a suitable cost-effective means of improving energy efficiency. Retrofitting involves upgrading an old building with advanced materials, techniques, and technology to discover a particular modified outcome. In this context 'retrofit' refers to technological implementations that result in energy conservation measures (ECMs) intended to improve the energy efficiency of a building [7]. The objective of energy retrofits is to improve a building's energy efficiency by implementing a variety of energy conservation opportunities (ECOs) and energy efficient measures at an economical cost [7]. Retrofit techniques use ECMs that are technological upgrades for electric lighting, building envelope, equipment, heating, ventilation, and air conditioning (HVAC), hot water generation and other electrical building services. [8] carried out energy audit techniques (EAT) to identify ECOs and found that retrofitting a building with ECOs can save up to $49.3 \%$ of the building's annual energy consumption [8]. A study carried out by [9] showed that the three most commonly installed energy efficient technologies in high performance buildings (HPBs) are daylighting, high efficiency HVAC systems and improved building envelope. The effectiveness of these 
technologies depend on the specific building characteristics such as location, size, orientation of the building, operation building envelope, electrical heating, cooling and ventilation system properties [9]. One of the conclusions from a study carried out by [10] was that the integrated effects of the ECMs does not equate to the sum of individual ECMs, therefore the total effectiveness of ECMs depends on the interaction between all ECMs [10]. [11] evaluated and simulated various ECMs divided into three categories: major investment ECMs, minor investment ECMs and zero investment ECMs. The results of their study showed that the ECMs implemented in the building considered can save up to $41.87 \%$ of energy without compromising occupant thermal comfort [11]. A study by [12] estimated the cost effectiveness of energy efficiency measures in new commercial buildings and the results showed that conventional energy efficiency technologies can reduce energy consumption in by $20 \%$ to $30 \%$ and up to over $40 \%$ for some building types and locations [12]. The above studies show that retrofits are a cost-effective way of implementing ECMs to improve the energy efficiency of old buildings, thus making them more sustainable and effective.

\subsection{Aim and Objectives}

This study aimed to conduct a quantitative analysis of the energy savings after retrofitting of ECMs implemented in a state-owned commercial building to determine the electrical energy savings, the effectiveness of energy efficient retrofits, and the correlated cost implications. An energy audit was carried out to determine the most suitable, cost-effective ECM retrofits to install in the building. Utility bills were used to establish the baseline data. The implementation of ECMs was monitored for a period of one year after which the results were analysed. ECO's and barriers to energy efficiency observed through this experiment are highlighted. The electrical consumption obtained from the ECMs was compared with the baseline data to evaluate the improvements in energy consumption of the building and assess the level of energy efficient improvements. An estimated cost savings was calculated associated with the implementation of energy efficient measures. The results from this experimental study can be used to implement cost effective and efficient retrofits in buildings and to improve on energy efficient retrofits as well as be used to develop policies and national government standard specifications.

\section{DESCRIPTION OF THE FACILITY}

The building in this case study was established in 1971 in Durban and provides jurisdictional services to the public. An image of the facility is shown in Figure 1. The building has 12 floors, consisting of a basement $\left(2252.31 \mathrm{~m}^{2}\right)$, ground floor $\left(14524.54 \mathrm{~m}^{2}\right), 1^{\text {st }}$ floor $\left(12540.54 \mathrm{~m}^{2}\right), 2^{\text {nd }}$ floor $\left(4097.15 \mathrm{~m}^{2}\right)$ and then the $3^{\text {rd }}$ floor to the $12^{\text {th }}$ floor have the same internal building layout with each floor spanning an area of $1874.10 \mathrm{~m}^{2}$. The total area of the building is $52155.54 \mathrm{~m}^{2}$.

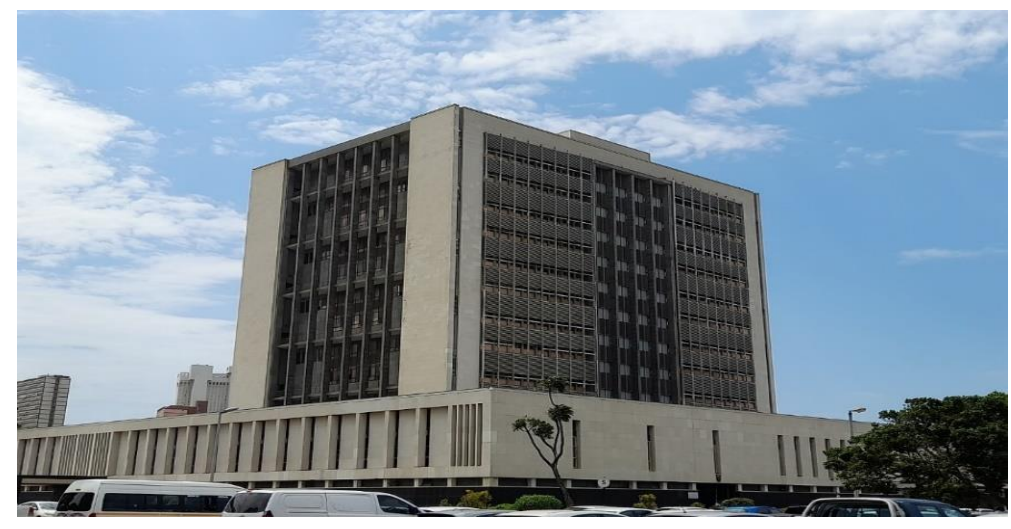

Figure 1: Experimental Commercial Building 
Being an old building there were no control systems in place to monitor and adjust the use of electricity consuming systems, neither were there any ECMs implemented. In 2008 the building was fitted with two gear-driven centrifugal water-cooled chillers and three cooling towers. The chiller consists of a compressor (with motor power rating of 380 volts $\mathrm{AC}, 50 \mathrm{~Hz}$ and 3 phase), oil pump motor (with power rating 380 volts $\mathrm{AC}, 50 \mathrm{~Hz}$ and 3 phase), the oil tank heater (with power rating of 115 volts $\mathrm{AC}, 50 \mathrm{~Hz}$ and 3 phase) and a control circuit (with power rating 115 volts $\mathrm{AC}, 50$ $\mathrm{Hz}$ and 3 phase). The refrigerant system is filled with $340 \mathrm{~kg}$ of R-134A refrigerant, with a working pressure range of 15.2 bars on the low and high sides.

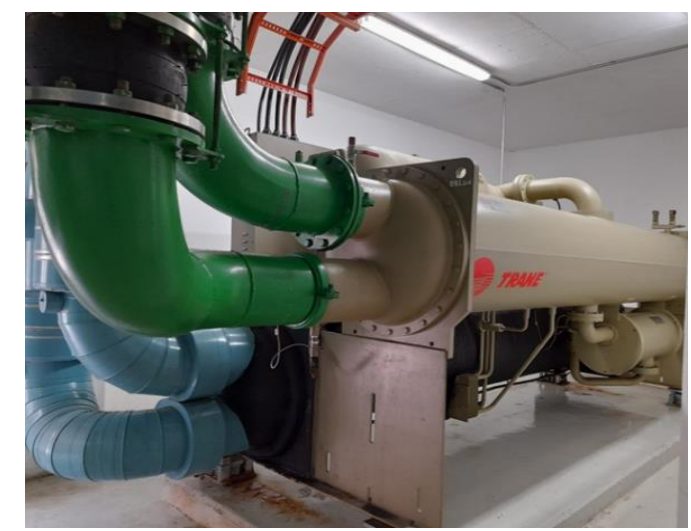

Figure 2: Chilled Water and Condenser Water Piping

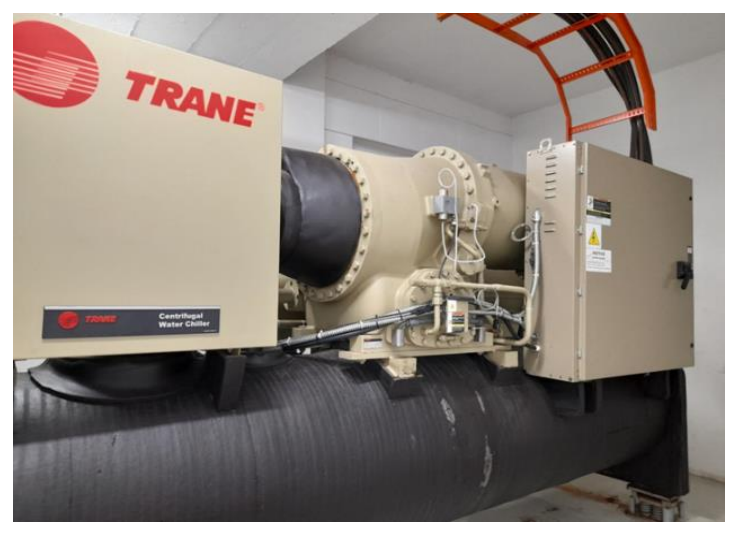

Figure 3: Centrifugal Water-Cooled Chiller

The facility had $58 \mathrm{~W}$ T12 fluorescent lamps with magnetic ballasts, and the lighting system had a manual switch which depended on a person to switch it on and off. The use of magnetic ballasts uses the sudden spike in the physical disruption of current in an inductive circuit to produce a high voltage that is required for starting up, thereafter it relies on a reactive voltage drop to reduce the voltage applied across the lamp [13]. Prior to the installation of the control automatic on/off switch and the variable frequency drives, the system operated throughout the day and over the weekends. It is to be noted that the facility has only one municipal electricity meter.

\section{METHODOLOGY, MATERIALS, AND EQUIPMENT}

The measures taken to carry out this experimental case study is discussed in this section, concurrently describing the materials and equipment installed and used.

\subsection{Energy Audit}

A walk-through energy audit was conducted to identify suitable ECMs that could be implemented in the building. The aim of the audit was to identify suitable technical retrofits that could be easily implemented to achieve reduction of electricity consumption in hours of operation, air conditioning loads, lighting loads and off-peak loads, as well as to define the energy boundaries. Energy boundaries in this case refers to the sources of energy and the extent of energy consumption.

The energy audit consisted of analysing energy consumption and relevant costs using utility bills. Other documentation like drawings and technical specifications were also reviewed to understand the electrical systems in the building. The facility manager was interviewed to gather technical and administrative information like electricity usage patterns, the operation of the facility and energy management, and to obtain technical drawings and archived reports/studies. The reason for a detailed analysis was to determine annual trends and fluctuations in the energy 
consumption with the associated costs and to draft a list of possible energy saving actions to be taken.

The brief walk-through energy audit involved a qualitative investigation of the electromechanical systems and the building shell. A checklist was used to identify key energy efficiency opportunities, for example the type of lighting used, the use of day/night sensors, types of motors or drives used, etc.

Upon completion of the site investigation and the data analysis, the potential ECMs were identified. The proposed ECMs were relatively simple and inexpensive. Thereafter a proposal of suitable housekeeping and minimum capital investment energy saving options as well as other potential ECMs identified with associated cost estimates were presented to the client.

\subsection{Establishing Baseline Data}

According to [14], a facility-level approach is suitable to use in order to determine baseline data. Utility bills were obtained from the local municipality and analysed, thereafter the energy consumption was recorded in Excel and a graph was generated. The average annual consumption was calculated over a period of four years, from 2008 to 2011 and then five years from 2015 to 2020 . The challenges faced were lack of accurate data collection resulting from poor document management, therefore not all utility bills were easily obtainable. All light fittings were counted, and all electrical equipment was taken into consideration. The power rating was then multiplied according to the number of hours used in a day and then multiplied by number of working days per year to obtain the total consumption per year. This calculation was compared with the utility bills to identify discrepancies and to consider electricity consuming equipment that should be operating under normal conditions. Upon establishing the baseline data, the energy use intensity (EUI) of the facility for the baseline year was calculated using equation (1). The EUI measures the facility's level of energy efficiency after the implementation of the retrofits and is often expressed as a function of the building size by identifying the annual energy usage per square area of the building.

Energy use intensity $=\frac{\text { Total annual energy consumption }}{\text { Total unit of output }}$

\subsection{Installation of ECM Retrofits}

For the purposes of this study, the system was retrofitted with VFDs for the pumps and a control system was installed to control the operating times of the system as well as the operation of the chilled water pumps and an on/off switch. The remote-control panel is situated outside the HVAC plant room, the main control panel is situated within the basement HVAC plant room, and the remote controlled 24 volts AC relays are located within each of the following switch gear panels - chillers, pumps, and fans.

The centrifugal water-cooled chiller was programmed to follow the following sequence of operation:

- Between Monday to Friday the data log timer was set to switch off the HVAC system at $18 \mathrm{H} 00$, this time could be set according to the building operating times.

- The data log timer was programmed to switch on the HVAC system at $06 \mathrm{H} 00$ between Monday and Friday, this time could be set according to the buildings operating times. 
- $\quad$ The HVAC system was set to be switched off over the weekends.

- A remote-control panel installed in the control room, was able to manually switch on and off the HVAC system. A time delay off-timer automatically switched off the HVAC system after being manually switched on.

- The chilled water pumps were programmed to start $3 \mathrm{~min}$ before the condenser water pumps which was programmed to start $3 \mathrm{~min}$ before the chiller started up. Therefore, there was a 6 min delay before the chiller started up. The chiller was programmed to stop 6 min before the pumps stopped operating.

\section{a) Automatic On/Off Control Switch}

An Orbis data log time switch is a digital time switch that was installed to automatically switch on and off the HVAC system from $06 \mathrm{H} 00$ to $18 \mathrm{H} 00$. Figure 4 shows the data logger used. The connection scheme for this automatic on/off control switch is shown in Figure 5. Figure 6 shows a graphical representation of the response during weekday operating hours. Figure 14 shows the Orbis data log timer switch installed in the control panel, identified by the DL-T set data logger. The Orbis data log timer was connected to an electric circuit operating from the main power supply via a relay. The functionality of this data logger allowed for easy programming. It can contain up to 40 programs, is easy to activate and deactivate and can be used temporarily or permanently.

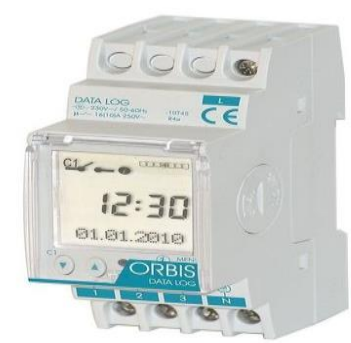

Figure 4: Orbis Data Log Timer

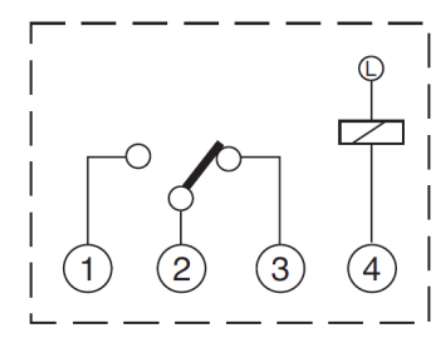

Figure 5: Connection Scheme - 1 Change over Switch [23]

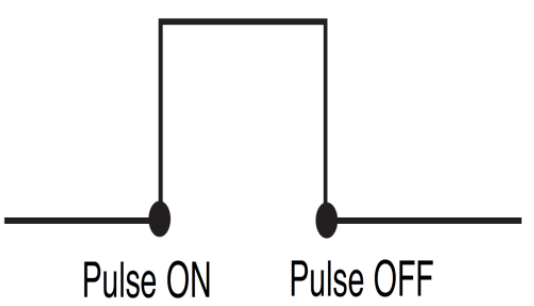

Figure 6: Step input from $06 \mathrm{HOO}$ to $18 H 00$

\section{b) Time Delay Switches and Multifunction Timer}

An ACDC multifunction multi range (MFMR) timer was installed to allow the HVAC system to run for a maximum of $4 \mathrm{~h}$ before shutting down the system. When the system detects a power supply, the relay energises lighting up the light emitting diode (LED) and the timer starts. After the time period programmed, for example $t$, has elapsed, the relay de-

energises and the LED goes off. See Figure 7 and

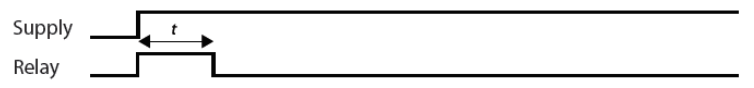

Figure 8 for the output relay signal indicating that the relay is energised for time $t$ even though the supply power is switched on for a longer period. Figure 9 shows the switch installed on site to switch off the HVAC system when manually switched on. 


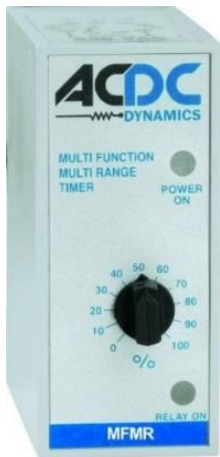

Figure 7: ACD Multifunction Multi Range Timer

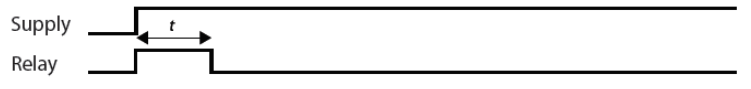

Figure 8: Output of the MFMR timer

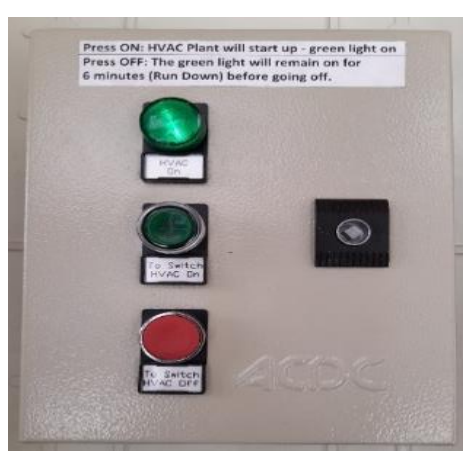

Figure 9: Switch for Manual Operation of the HVAC System

An ACDC delay-on timer was installed in the wiring circuit for the chiller system in Figure 14 and shown in Figure 10. With this timer the applied voltage triggers the time delay relay, and when the delay begins, the power LED will be on. When the set delay time expires, the relay will energise, and the relay LED will turn on as shown by Figure 11. The timer will then remain in power until the system is turned off. With reference to Figure 14, the delay on the timer is connected in parallel with the MFMR timer and the automatic on/off control switch. The delay on the timer will allow the chiller system to start up 6 min after the power has been switched on manually or automatically by the Orbis data log timer switch.
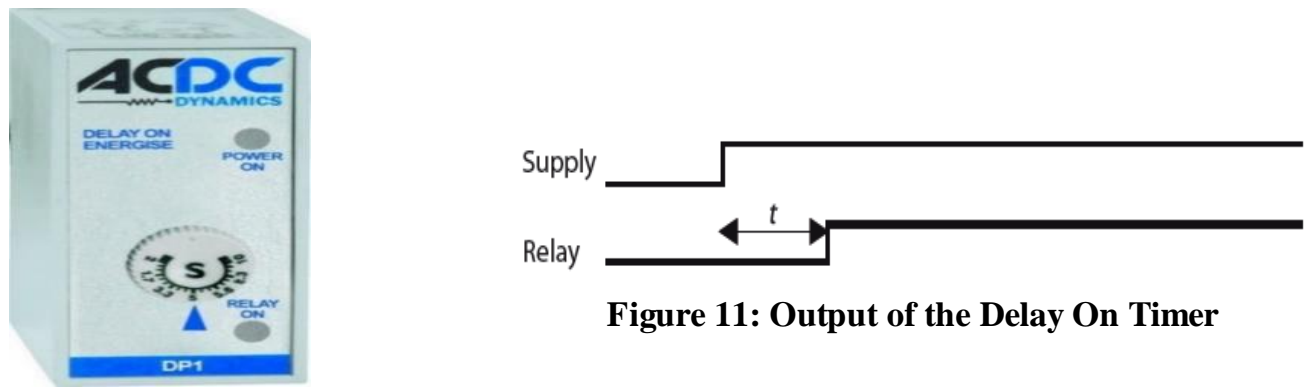

Figure 11: Output of the Delay On Timer

Figure 10: ACDC Delay on Timer

An ACDC delay-off timer was installed in the wiring circuit for the chiller system to switch off the pumps 6 min after the chillers were powered off. With this timer, the supply voltage energises the relays lighting up the power LED and the relay LED. When there is no voltage supply, the Inst. contact relay de-energises and the delay time starts. When the time delay period, $t$, expires, the time delay de-energises and the relay LED goes off, Figure 13. With reference to Figure 14 , one can see that the delay-off timer was connected in parallel to the automatic on/off switch, the MFMR timer and the delay-on timer. The delay-off timer was connected to the circuit to delay shutting off the pumps by 6 min after the system was switched off. Figure 12 shows the delay-off timer and Figure 13 shows the output signal of the relay. 


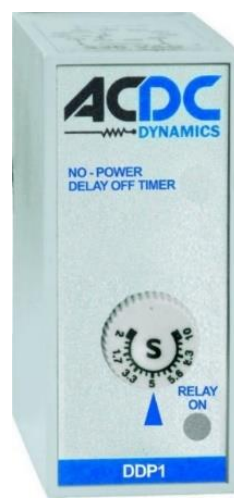

Figure 12: ACDC Delay off Timer

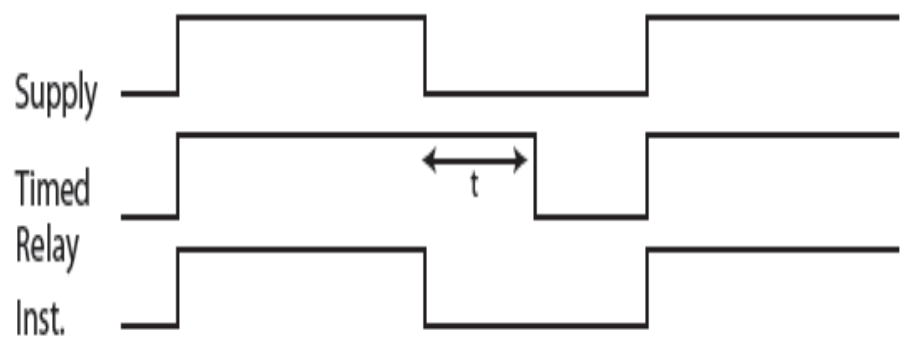

Relay

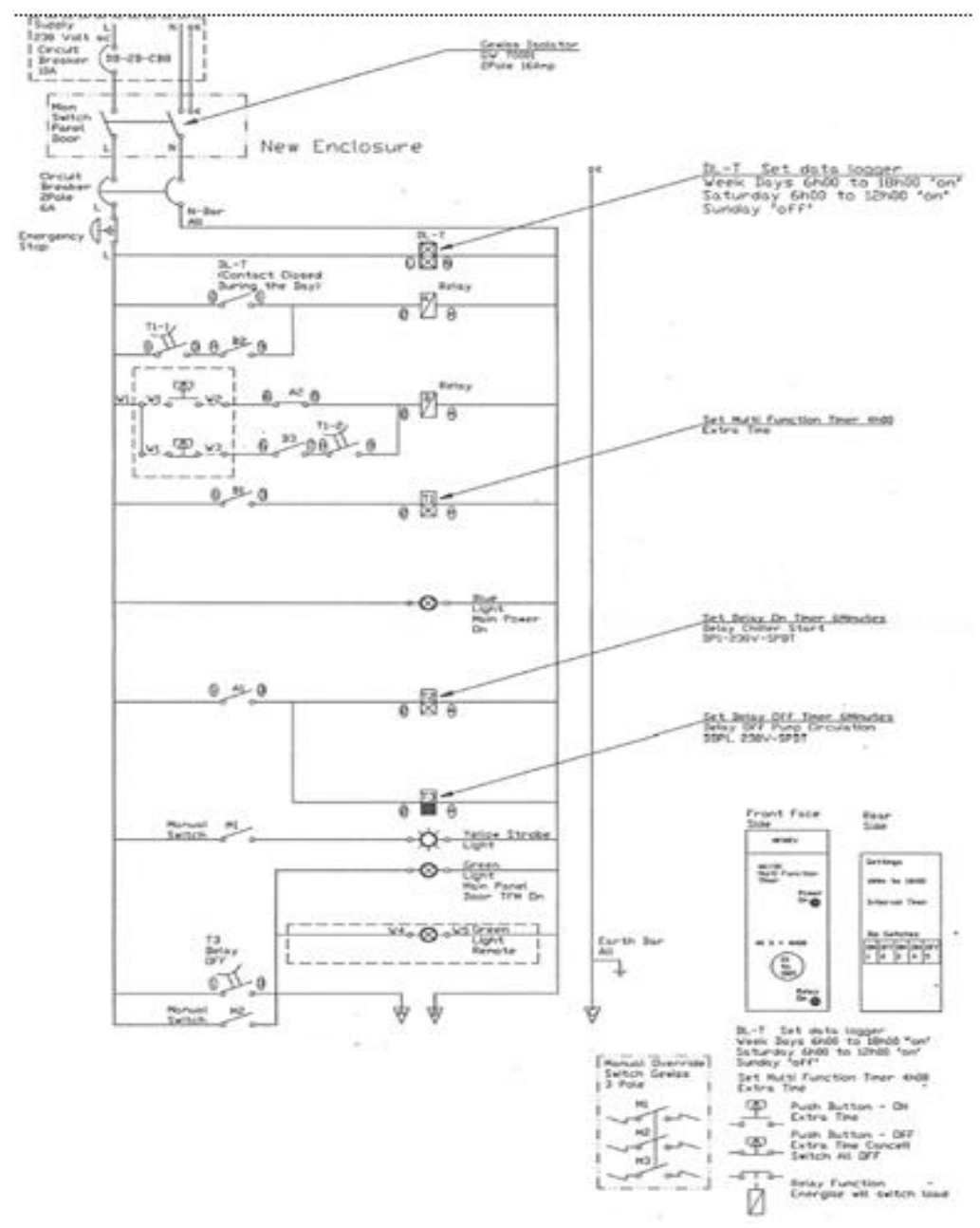

Figure 14: Control Panel Wiring diagram

\section{c) Variable Frequency Drives - VFDs}

WEG CFW700, WEG CFM500 and the INVT Goodrive 200 Inverter variable frequency drives were installed to regulate the $3 x$ cooling tower fan speeds according to the system requirements (Figure 15, Figure 16 and Figure 17). VFDs were only installed in the cooling towers (Figure 11). CWF700 is a high performing VFD that controls the speed and torque of three-phase AC induction motors. The incoming AC current with a fixed frequency is converted into a voltage with variable amplitude and frequency, resulting in a voltage conversion. 


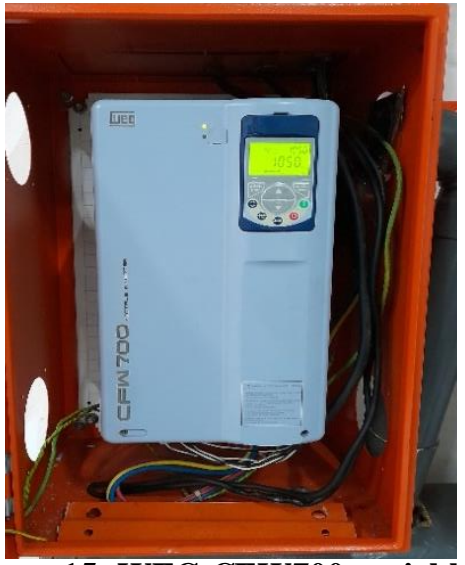

Figure 15: WEG CFW700 variable frequency drive

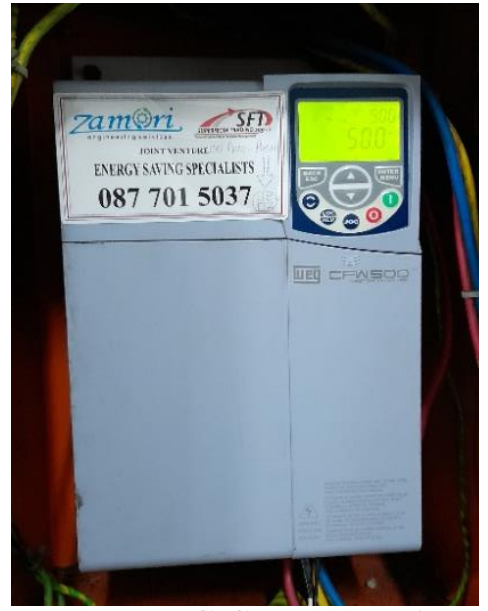

Figure 16: WEG CFM500 variable frequency drive

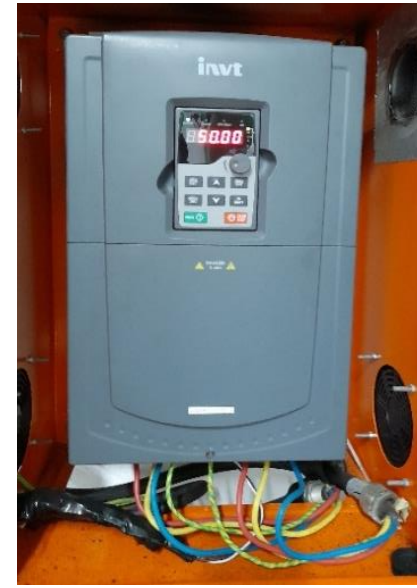

Figure 17: INVT Goodrive 200 Inverter variable frequency drive

The VFDs were connected to the cooling tower control wiring to regulate the fan speed. The integrated proportional-integral capabilities of VFDs to automatically adjust fan speeds as conditions vary, while maintaining the required flow, eliminates the need for an external set-point controller [15]. Therefore, by reducing the speed of the motor, the VFD can reduce the energy consumed by the fan. With reference to Figure 17, the power of the fan was directly proportional to the cube of its speed, therefore small speed reductions resulted in large power reductions [15]. VFDs act as soft starters, increasing/decreasing speed at a programmable rate, thus reducing the large amounts of energy consumed when starting the fan [15]. These capabilities of VFDs ultimately optimize the fan speed to maintain the temperature of the condenser water leaving the cooling tower.

\section{d) Lighting System Retrofits}

All the T12 fluorescent lights were replaced with T8 $36 \mathrm{~W}$ fluorescent lights with electronic ballasts and telescopic lamp holders. All outdoor lighting was replaced with $16 \mathrm{~W}$ lamps. Motion sensors were installed within the facility, except for the spaces that did not allow for motion sensors due to their function. Day-night switches were installed in the passages and for the outside lights of the facility. Figure 18 shows the type of day-night switch installed. 


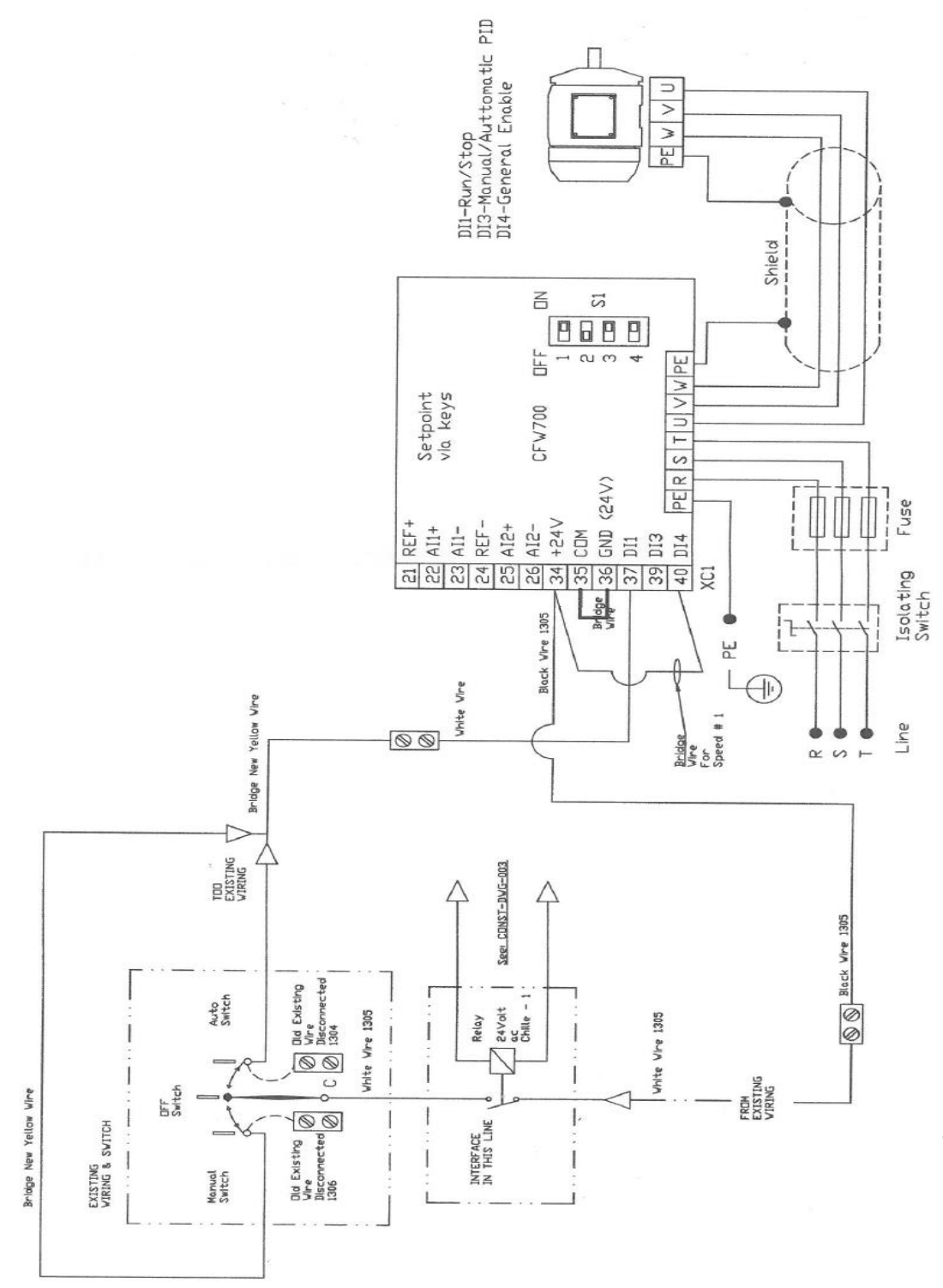

Figure 18: Circuit wiring diagram showing the VFD connection

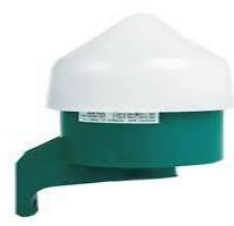

Figure 19: Day-Night Switch Installed in the Facility

\subsection{Data collection}

Power Watch ${ }^{\mathrm{TM}}$ is software used to monitor and record utilities. PowerWatch ${ }^{\mathrm{TM}}$ software was used to monitor the energy consumption of the HVAC system in real time from a remote location. Data was collected before and after the ECMs were implemented to compare the energy consumption and the effect the retrofits had on the total energy consumption of the retrofits. Smart meters were installed to monitor and record the amount of electricity consumed by the lighting and the HVAC systems. The smart meters supplied input data to PowerWatch ${ }^{\mathrm{TM}}$ which recorded and monitored the data. 


\section{RESULTS AND DISCUSSION}

This section provides the energy consumption results obtained from the installation of the ECM retrofits and compares these to the results prior to the installation of the retrofits to determine the impact that the ECM retrofits had on improving the energy efficiency of the facility.

\subsection{Energy Audit}

On completion of the walk-through audit, it was concluded that the facility was not energy efficient and the following ECMs could be implemented to improve the efficiency of the building:

- All light bulbs to be replaced with more energy efficient lighting.

- Day/night switches to be installed for all outdoor lighting and lighting in the communal passages.

- Occupancy sensors to be fitted in the remaining spaces.

- $\quad$ The HVAC to be fitted with an automatic on/off switch.

- VSDs to be installed for the cooling tower fans.

The utility bills were analysed from which the baseline data was established, and electricity cost for energy consumption was determined. This report only discusses the implementation of the HVAC retrofits.

It is essential to compare expenditure on the ECM and the savings over the lifetime of the ECM equipment because most ECMs have a delayed reward, i.e. expenses come at the beginning of a project while the benefits come later [16]. For an energy efficient retrofit to be financially feasible the capital investment needs to be lower than the sum of savings obtained by the reduction in operating costs over the lifespan of the ECM [16].

\subsection{Baseline Data}

A four-year period was used to establish the baseline data for the lighting interventions from January 2008 to December 2011 (refer to Table 1). ISO 50001 defines energy baseline as "quantitative reference providing a basis for comparison of energy performance" [17]. The baseline data was established taking into consideration the lights that were not working and other electricity consuming equipment that should be operable under normal circumstances.

Table 1: Monthly Electricity Consumption in kWh for a Period of four-Years from 2008 to 2011

\begin{tabular}{|l|c|c|c|c|c|}
\hline & Year 2008 & Year 2009 & Year 2010 & Year 2011 & Baseline 1 \\
\hline & $\mathbf{k W h}$ & $\mathbf{k W h}$ & $\mathbf{k W h}$ & $\mathbf{k W h}$ & $\mathbf{k W h}$ \\
\hline January & 368000 & 420000 & 387875 & 436000 & 589612,9 \\
\hline February & 495642,9 & 480000 & 492000 & 476000 & 495642,9 \\
\hline March & 532357,1 & 316000 & 472000 & 476000 & 532357,1 \\
\hline April & 472000 & 364000 & 464666,7 & 496000 & 496000 \\
\hline May & 432000 & 353821,1 & 355333,3 & 360000 & 440000 \\
\hline June & 344000 & 312195,1 & 380000 & 324000 & 380000 \\
\hline July & 352000 & 322601,6 & 252000 & 292000 & 368000 \\
\hline August & 408000 & 291382,1 & 352000 & 252000 & 408000 \\
\hline September & 340000 & 355555,6 & 328000 & 284000 & 376000 \\
\hline October & 450876,4 & 355555,6 & 356000 & 236000 & 450876,4 \\
\hline November & 409887,6 & 288888,9 & 420000 & 256000 & 420000 \\
\hline
\end{tabular}




\begin{tabular}{|l|l|l|l|l|l|} 
December & 355236 & 468125 & 380000 & 192000 & 468125 \\
\hline
\end{tabular}

Figure 20 graphical representation of the facilities energy consumption from 2008 to 2011 . The light blue graph, BASELINE, indicates the datum line against which the ECM was measured. Noteworthy is that in 2010 energy efficient lighting, occupancy sensors and day/night switches were installed in the facility resulting in a decrease in energy consumption by the end of 2011. The other varying trend lines could be as a result of other factors such as load shedding, downtime of electro-mechanical equipment and social dynamics (for example protests or labour strikes).

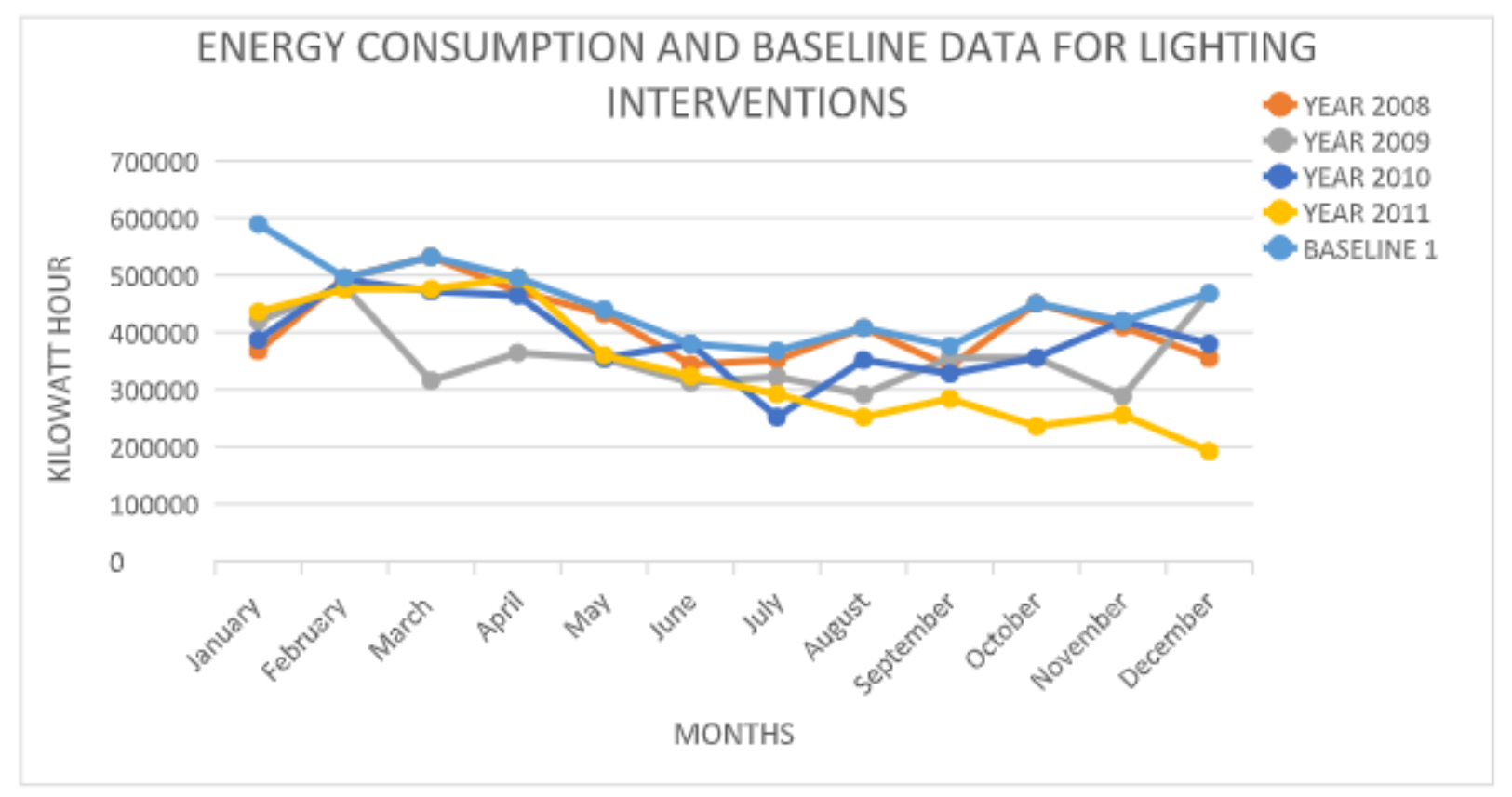

Figure 20: Monthly Electricity Consumption in $\mathrm{kWh}$ and Baseline Data for

Lighting Interventions from 2008 to 2011

A 5-year period was used to establish the baseline data starting in 2015 and ending in 2020. Table 2 provides a breakdown of the energy consumed by the facility from April 2015 to November 2020.

Table 2: Monthly Electricity Consumption in kWh for a Period of five-Years

\begin{tabular}{|l|c|c|c|c|c|c|c|}
\hline & Year 2015 & Year 2016 & $\begin{array}{c}\text { Year } \\
\mathbf{2 0 1 7}\end{array}$ & $\begin{array}{c}\text { Year } \\
\mathbf{2 0 1 8}\end{array}$ & $\begin{array}{c}\text { Year } \\
\mathbf{2 0 1 9}\end{array}$ & $\begin{array}{c}\text { Year } \\
\mathbf{2 0 2 0}\end{array}$ & Baseline 2 \\
\hline & $\mathbf{k W h}$ & $\mathbf{k W h}$ & $\mathbf{k W h}$ & $\mathbf{k W h}$ & $\mathbf{k W h}$ & $\mathbf{k W h}$ & $\mathbf{k W h}$ \\
\hline January & & 354000,00 & 354000 & 420000 & 417000 & 387000 & 479357,9 \\
\hline February & & 399000,00 & 318000 & 432000 & 294000 & 348000 & 487357,9 \\
\hline March & & 532357,1 & 375000 & 348000 & 393000 & 303000 & 497357,9 \\
\hline April & 489000 & 314689,70 & 441000 & 492000 & 324000 & 321726,3 & 498357,9 \\
\hline May & 390000 & 255000,00 & 423000 & 351000 & 393000 & 268105,3 & 467357,9 \\
\hline June & 435000 & 279000,00 & 351000 & 378000 & 279000 & 259168,4 & 410357,9 \\
\hline July & 393000 & 228000,00 & 351000 & 381000 & 306000 & 255000 & 418011 \\
\hline August & 444230 & 258000 & 384290,3 & 435000 & 210000 & 240000 & 452357,9 \\
\hline September & 380769,2 & 312000 & 242709,7 & 306000 & 270000 & 243000 & 431357,9 \\
\hline October & 330000 & 255000 & 270000 & 348000 & 270000 & 318000 & 425357,9 \\
\hline November & 297000 & 276000 & 300000 & 282000 & 354000 & 303000 & 539357,9 \\
\hline
\end{tabular}


Figure 21 shows the overall energy consumption. The green graph, BASELINE, indicates the datum line against which the ECM was measured. The HVAC ECMs were installed in 2019 and by 2020 dramatic reductions in energy consumption could be seen. The other varying trend lines could be as a result of other factors such as load shedding, downtime of electro-mechanical equipment and social dynamics (for example protests or labour strikes).

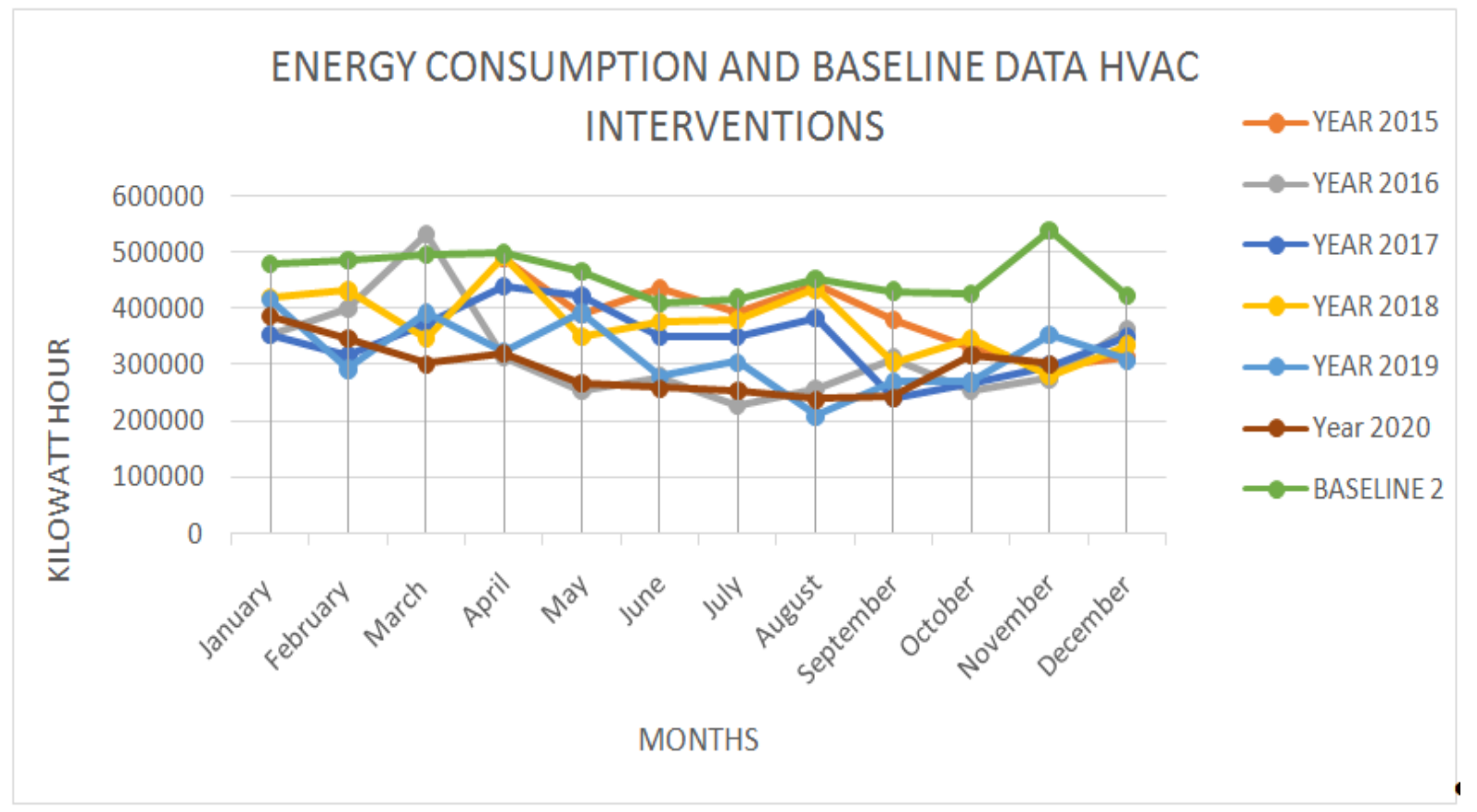

Figure 21: Monthly Electricity Consumption in kWh and Baseline Data

\subsection{Data Analysis}

Figure 22 indicates the energy consumption in kWh for the five-month period between 17 August 2015 to 17 December 2015. This graph was generated by PowerWatch ${ }^{\mathrm{TM}}$ software and indicates the total building energy consumption after the implementation of lighting interventions. With reference to Figure 22, before the 18 Oct period, the troughs of the graph hovered around $400 \mathrm{kWh}$ each day, indicating that the minimum energy consumed in the day was $400 \mathrm{kWh}$ even when there was no activity in the building. The maximum peak was $603.876 \mathrm{kWh}$ whereas the average peak consumption was between $550 \mathrm{kWh}$ and $600 \mathrm{kWh}$. After the $18 \mathrm{Oct}$, it is clear that the graph troughs were reduced to below $150 \mathrm{kWh}$, with the minimum trough around $117.83 \mathrm{kWh}$. The overall trend of the electricity consumption can be viewed by the grey graph below the $\mathrm{x}$-axis of the blue graph in Figure 22. 


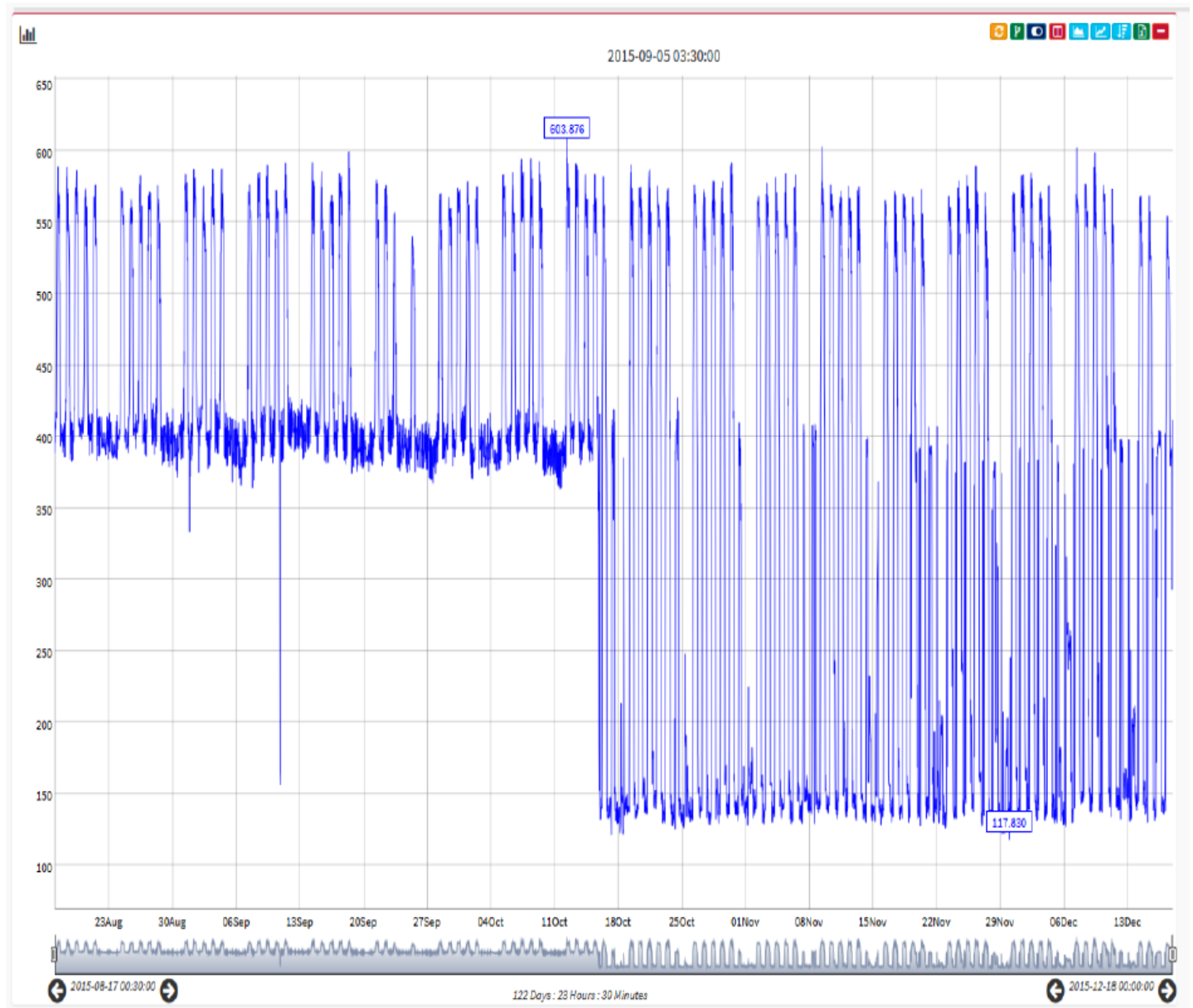

Figure 22: Energy Consumption (in kWh) from 17 August 2015 to 17 December 2015

Figure 23 shows the overall load profile of electricity consumption after the implementation of the lighting retrofits in 2015. There was a distinct reduction in the building's total electricity consumption after 2015.

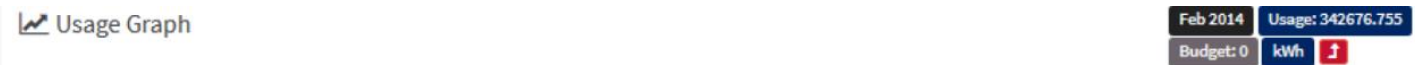

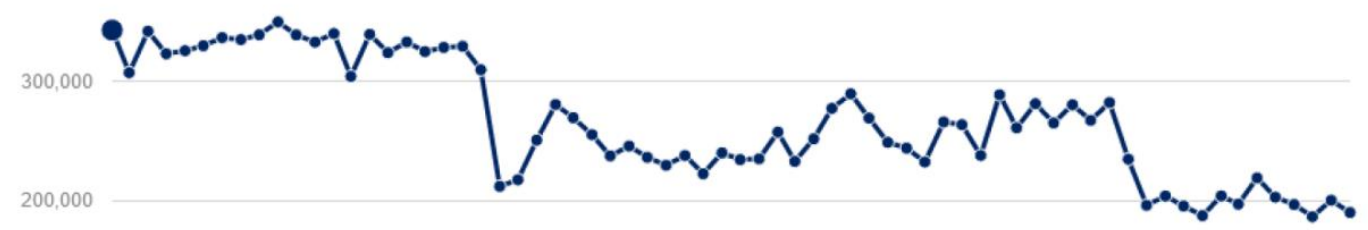

Figure 23: Total Electricity Load Profile over a Period of Five Years after the Implementation of the Lighting Interventions 
Figure 24 shows the total electricity consumption 2 months prior and 2 months post the implementation of the HVAC interventions corresponding to the period between 05 July 2019 and the 05 December 2019. Before the interventions were installed, the peaks reached around $250 \mathrm{kWh}$ and the troughs were slightly above $50 \mathrm{kWh}$. After the implementation of the HVAC energy efficient interventions, the peaks reached a maximum peak of $530.714 \mathrm{kWh}$ and the troughs reached a minimum of $0.546 \mathrm{kWh}$. The inconsistent spikes in the peaks after the interventions is a result of equipment and system testing and monitoring.

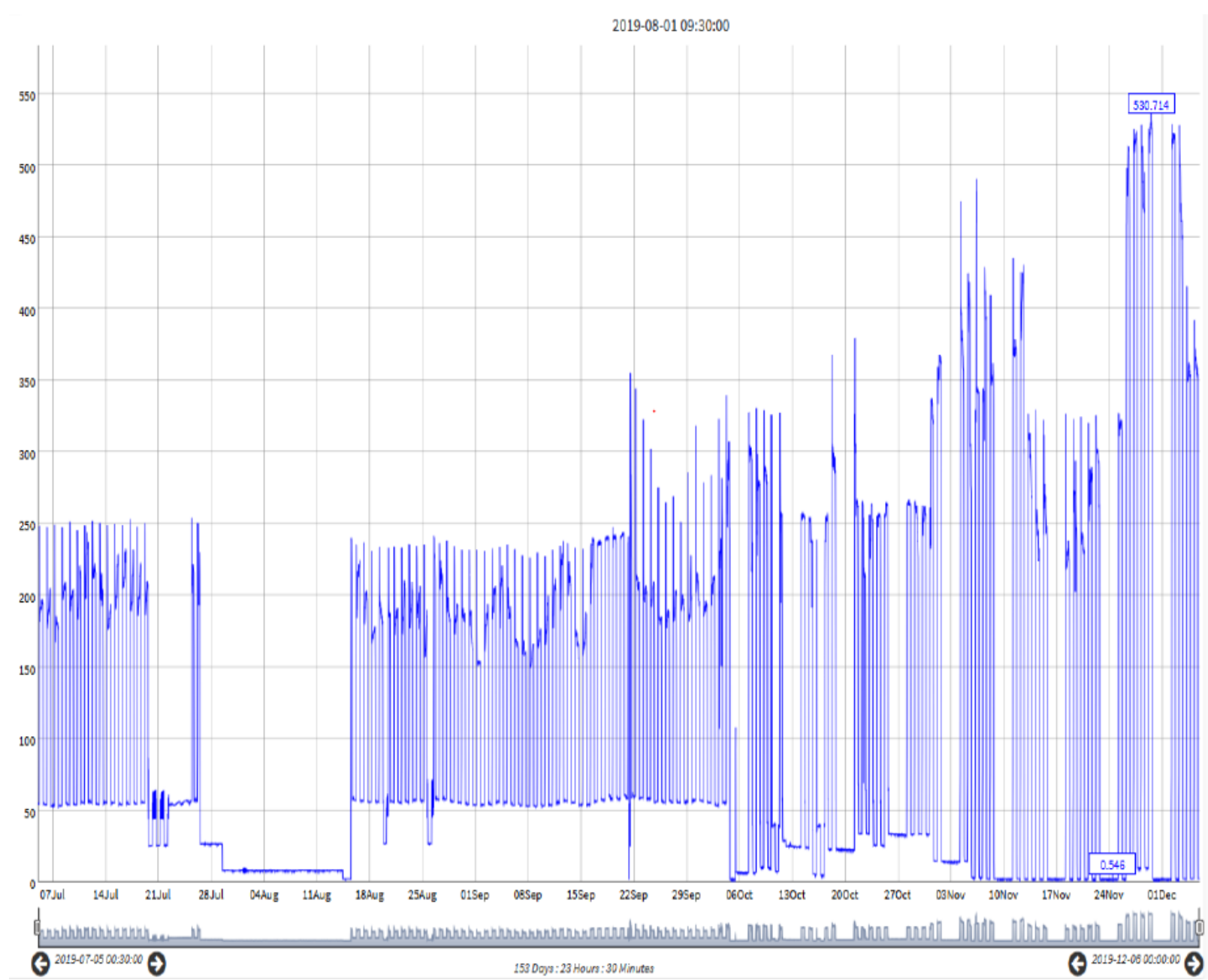

Figure 24: Total Energy Consumption after HVAC Interventions in 2019

Figure 25, generated by PowerWatch ${ }^{\mathrm{TM}}$, shows the total building energy consumption in $\mathrm{kWh}$ before the installation of ECM, for the period from 01 January 2019 to 28 January 2019. According to PowerWatch ${ }^{\mathrm{TM}}$, the total energy consumed was $137808 \mathrm{kWh}$. At the beginning of January, the troughs of the graph were around $40 \mathrm{kWh}$ then towards the end of the month the troughs dipped just below $40 \mathrm{kWh}$. The peaks of the graph are not very consistent during this period, with the highest peak reaching approximately $540 \mathrm{kWh}$. At this stage energy was still being consumed every day of the week including public holidays and weekends, as indicated by the graph. 


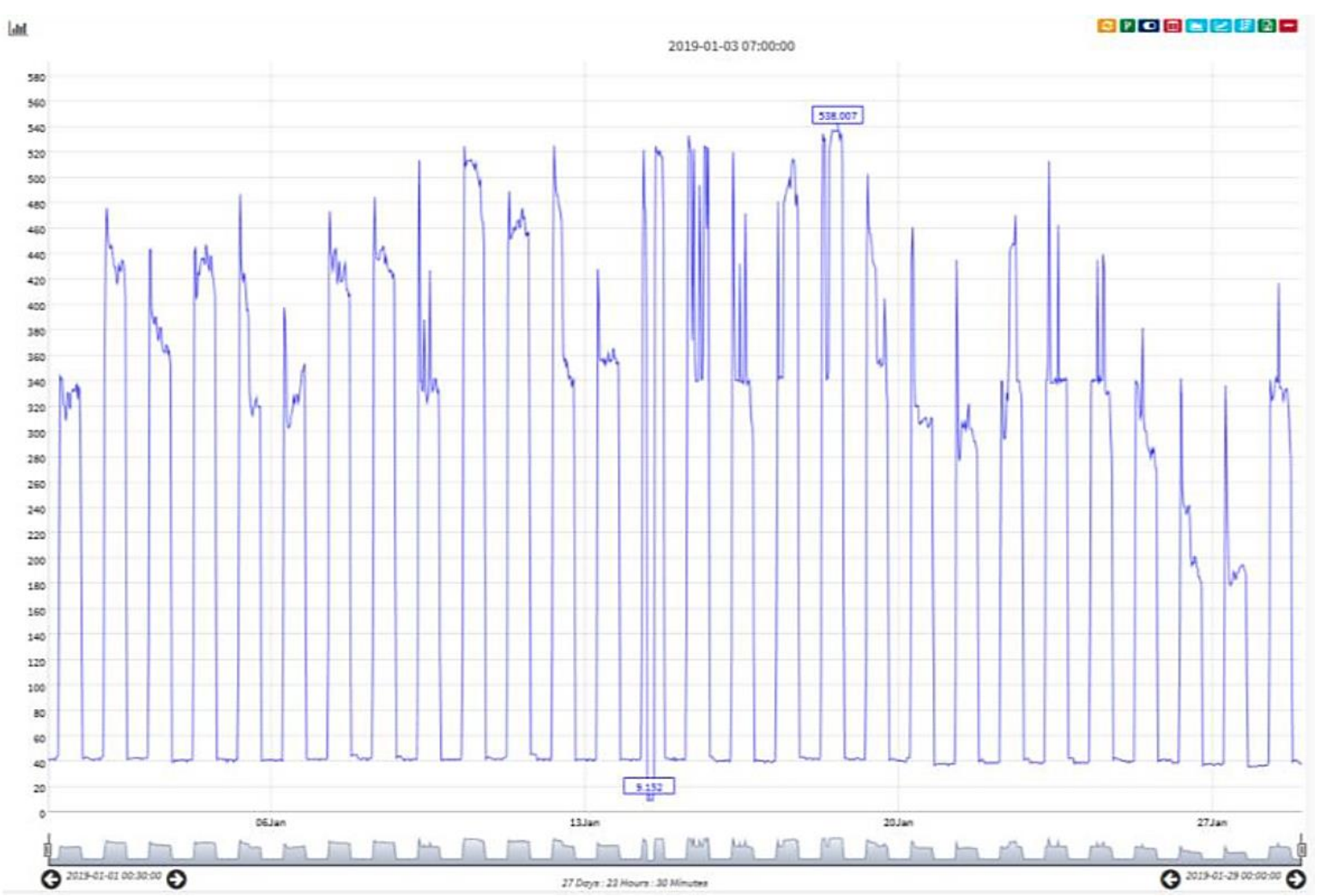

Figure 25: Energy Consumption (in kWh) from 01 January 2019 to 28 January 2019

Figure 26 highlights the various discrepancies in energy consumption for the period between June 2019 and July 2019, which is prior to the HVAC energy efficient interventions. The blue blocks indicate that the HVAC system was not switched off during off-peak periods by the main BMS systems used for the lighting. The green block shows that the lighting control system was working as designed. The HVAC pumps were not yet connected to the existing BMS, causing the night load as highlighted by the orange block in Figure 26.

Figure 27 shows the total energy consumption between 01 January 2020 and 28 January 2020 after the HVAC ECMs had been implemented. According to PowerWatch ${ }^{\mathrm{TM}}$, the total energy consumed for this period was $100286 \mathrm{kWh}$. The maximum amount of energy consumed according to Figure 27 as slightly under $560 \mathrm{kWh}$. The troughs of Figure 27 show that $0 \mathrm{kWh}$ of energy was consumed during off-peak periods. The low energy consumption during the beginning of January, where many building occupants are still on annual leave, show that the system regulated itself according to the load required. The $4^{\text {th }}$ and $5^{\text {th }}$ of January was a weekend, and the graph shows that there was no energy consumption. However, from the $6^{\text {th }}$ of January the graph peaks are relatively constant at between $520 \mathrm{kWh}$ and $540 \mathrm{kWh}$ for the rest of the 5 working days, thereafter the graph drops to $0 \mathrm{kWh}$ over the weekend, which shows that the ECM implemented shut the system off completely and the automatic on/off switch functioned according to its programming. 


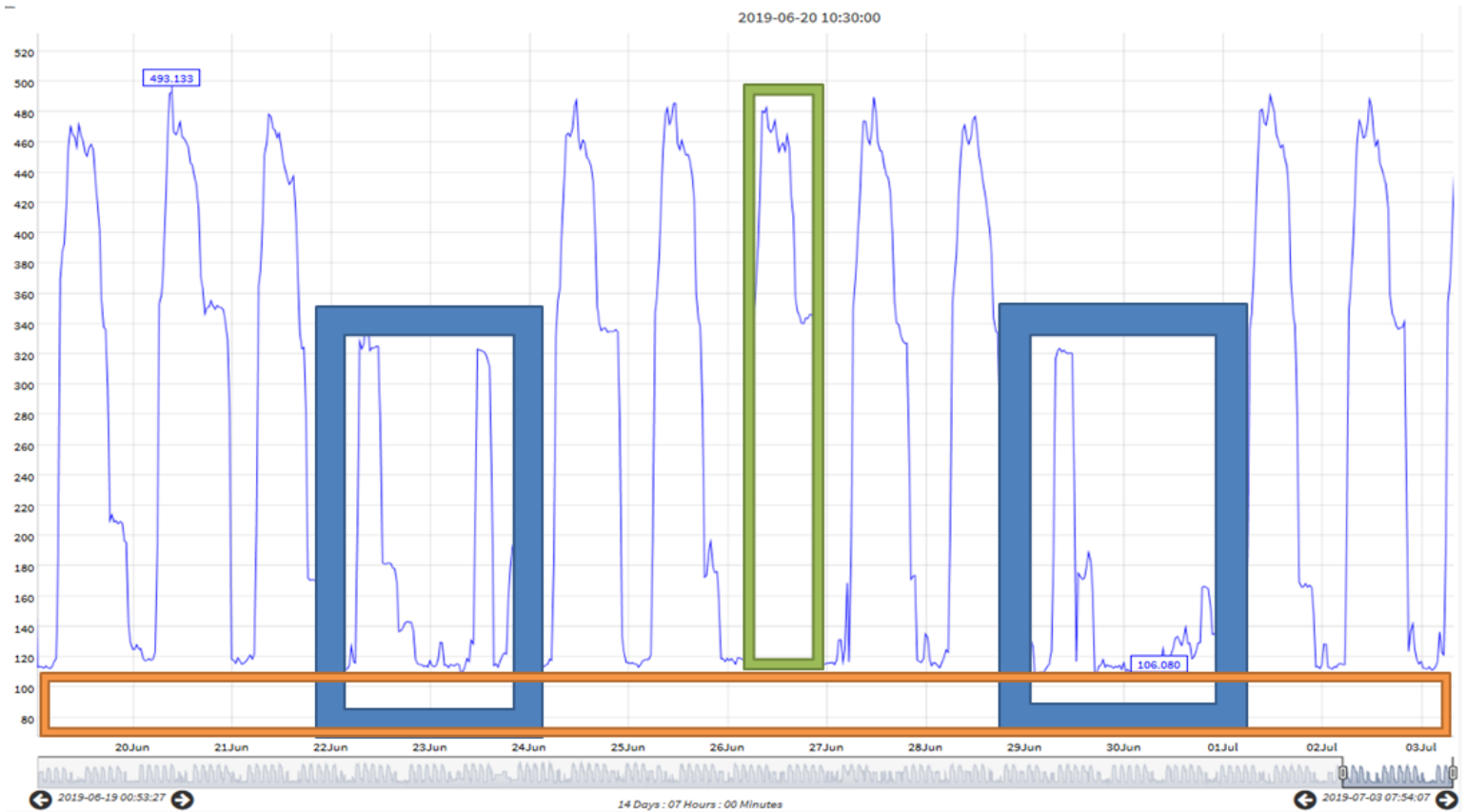

Figure 26: Highlighting the Anomalies in the Graph

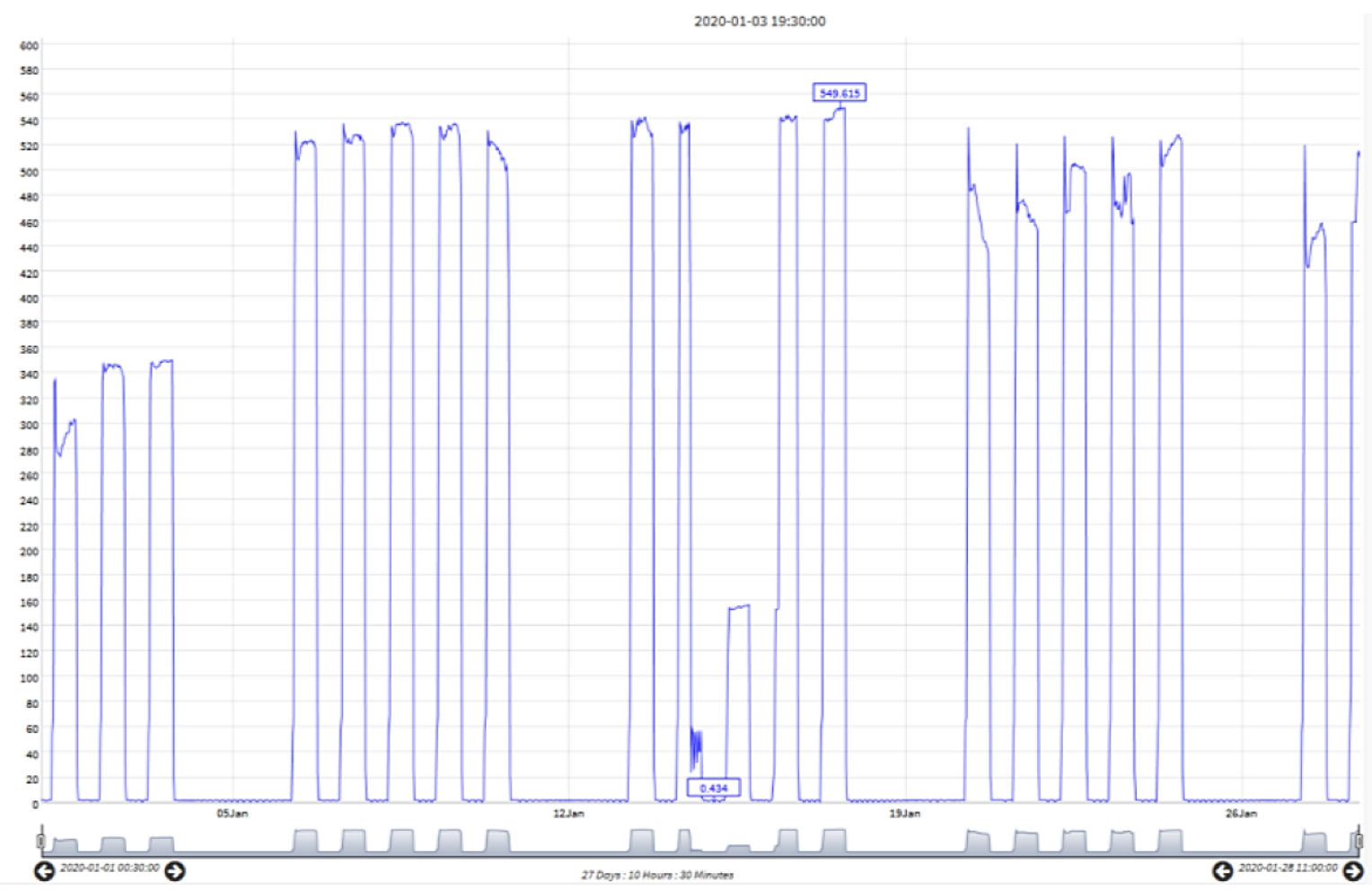

Figure 27: Energy Consumption (in kWh) from 01 January 2020 to 28 January 2020

Using the baseline data for January from Table 2, the energy consumption for that month was calculated to be $589000 \mathrm{kWh}$ for 31 days. Using the PowerWatch ${ }^{\mathrm{TM}}$ software, the total energy consumption for January 2020 was 190569 $\mathrm{kWh}$, therefore the realised saving was $67.65 \%$. This energy savings percentage is rather high when compared to other research results; this can be attributed to the fact that the facility's electricity consuming systems were operational daily, which means that the facility management team were not regularly switching off the lights and the HVAC systems according to the usage of the building. Implementing automatic on/off switches cuts down the total electricity usage by 50 
$\%$, with the other $17 \%$ representing a reduction due to the control system that regulates the HVAC system according to the use and the lighting occupancy sensors. Another aspect to consider is that the facility had been poorly managed - systems were not serviced on time and they were often left to operate continuously. This had a direct impact on the energy efficiency of the building previously, resulting in high energy consumption.

The EUI of the facility was calculated for the month of January using equation (1). The EUI before ECM retrofits had been implemented indicate that $5.9 \mathrm{kWh}$ of energy was consumed per square area of the facility. This is unreasonably high.

$$
\text { EUI before ECM retrofits }=\frac{\text { Total annual energy consumption }}{\text { Total unit of output }}=\frac{589000}{100000}=5.9 \mathrm{kWh} / \mathrm{m}^{2}
$$

The EUI after ECM retrofits had been implemented indicate that $1.9 \mathrm{kWh}$ of energy was consumed per square area of the facility.

$$
\text { EUI before ECM retrofits }=\frac{\text { Total annual energy consumption }}{\text { Total unit of output }}=\frac{190569}{100000}=1.9 \mathrm{kWh} / \mathrm{m}^{2}
$$

The energy efficient interventions dramatically reduced the building's energy consumption, thus improving the overall energy efficiency of the building.

\subsection{Financial Savings Achieved}

The lighting and HVAC interventions reduced the building's total energy consumption, therefore the amount paid for electricity was reduced.

\subsubsection{Lighting Savings}

The apparent total lighting load was calculated to be $277.395 \mathrm{kVA}$, therefore the actual lighting load in $\mathrm{kW}$ is calculated using equation (2) and assuming the power factor $=1$ to be $277.395 \mathrm{~kW}$.

$$
\text { Actual power }(k W)=\text { Apparent power }(k V A) \times \text { Power Factor }
$$

A total of an average of 10 hours of electricity consumption was saved per day, therefore the lighting system saved $2773.95 \mathrm{~kW}$ per day. Using an electricity tariff of R1.2 per kWh (2011 utility rate), the facility saved R3 328.74 per day and in a year a saving of R1 214990.10 was achieved.

\subsubsection{HVAC Savings}

The total estimated HVAC electricity savings per month was $6095.96 \mathrm{kWh}$ over the weekends and $568 \mathrm{kWh}$ during the week. Therefore, the total electricity savings for the month was $(6095.96 \times 4)+(568 \times 20)=35743.84 \mathrm{kWh}$. Using an electricity tariff of R1.0624 per kWh (2018 utility rate), the total saving per month was R57 275.93 and R687 311.16 over a year. The total savings achieved per month after the installation of both the HVAC and the lighting energy efficient interventions was R1 902301.26 per year.

\subsection{Prevalent Barriers to Energy Efficiency}

It was noted during the energy audit that the facility management team had not provided sufficient support or awareness when it came to managing the total energy consumption of the building, therefore the facility was consuming more energy that it should have. The staff and building occupants did not actively participate in energy conservation activities. The 
maintenance team were not regularly servicing the electricity consuming system to ensure that all components operated optimally. These factors play an important role in ensuring that the building operation is energy efficient. The lack of enthusiasm and commitment from the facility management team was a major barrier during the operation and maintenance of the ECM retrofits.

Lack of funds, another barrier to energy efficiency, prevented the installation of more advanced energy efficient systems, therefore simple and cost-effective retrofits were implemented. These retrofits have improved the energy efficiency of the facility, however, with the availability of funds other energy efficient measures could be sought such as the option of installing photovoltaic (PV) panels or other sources of renewable energy. South Africa, being a Third World country, lacks the resources to implement advanced energy efficient technology and control systems in public facilities because there are only a few services providers who can implement the advanced technological energy efficient measures and are the only ones that can service and maintain those systems. Knowing that, these companies then charge exorbitant prices for service and maintenance causing the ECM to become less financially feasible. Also, the parts for such advanced systems are not easily available in the country (in some cases they need to be imported) and are more costly.

\section{CONCLUSIONS}

This case study quantified the implementation of ECM and the improvement of energy efficiency of the facility. ECM retrofits saved an average of $398431 \mathrm{kWh}$ of electrical energy per month amounting to a $67 \%$ improvement in energy efficiency. The ECM retrofits improved the EUI of the building to $1.9 \mathrm{kWh} / \mathrm{m}^{2}$. The total financial savings achieved was R1 902301.26 per year. Barriers to energy efficiency were identified during the planning stages and during the operation of the building. Some of the barriers were related to lack of information and enthusiasm to participate in improving the energy efficiency of the building, lack of resources, and the lack of funds to improve energy efficiency.

\section{REFERENCES}

1. P. Howden-Chapman, "How real are the health effects of residential energy efficiency programmes?," Soc. Sci. Med., vol. 133, pp. 189-190, 2015, doi: 10.1016/j.socscimed.2015.03.017.

2. Banjie Godilano-Sarmiento \& Christia Almario-Guevara, "Students' Conceptual Understanding and Attitude on Climate Change Resilience and Mitigation Practices", International Journal of Educational Science and Research (IJESR) ,Vol. 6, Issue 2, pp, 7-16

3. D. Mudarri and W. J. Fisk, "Public health and economic impact of dampness and mold," Indoor Air, vol. 17, no. 3, pp. 226235, 2007, doi: 10.1111/j.1600-0668.2007.00474.x.

4. Alethea Dympep \& R. J. Singh, "A Test to Measure Knowledge of Farmers on Mitigation and Adaptation Practices of Climate Change in Hill Agricultural System", International Journal of Agricultural Science and Research (IJASR) ,Vol. 7, Issue 1, pp, $21-28$

5. M. Ringel, B. Schlomann, M. Krail, and C. Rohde, "Towards a green economy in Germany? The role of energy efficiency policies," Appl. Energy, vol. 179, no. 2016, pp. 1293-1303, 2016, doi: 10.1016/j.apenergy.2016.03.063.

6. J. YogaNarasimhulu Naidu \& P. Sivaraj, "Impact of Climate Change on Paddy Farmer's Livelihood Security in Erode and Tiruchirapalli Districts of Tamil Nadu ", International Journal of Humanities and Social Sciences (IJHSS) ,Vol. 5, Issue 6,pp; 103-106

7. N. Willand, I. Ridley, and C. Maller, "Towards explaining the health impacts of residential energy efficiency interventions - A 
realist review. Part 1: Pathways,” Soc. Sci. Med., vol. 133, pp. 191-201, 2015, doi: 10.1016/j.socscimed.2015.02.005.

8. C. Econometrics, "Assessing the Employment and Social Impact of Energy Efficiency Final report Volume 1: Main report," vol. 1, pp. 1-139, 2015, [Online]. Available: www.camecon.com.

9. P. Sivaraj \& H. Philip, "Role of Mass Media in Changing Awareness Level on Climate Change Among Small and Marginal Paddy Farmers of Tamil Nadu", International Journal of Humanities and Social Sciences (IJHSS) ,Vol. 5, Issue 4, pp; 45-50

10. S. Vojtovic, A. Stundziene, and R. Kontautiene, "The impact of socio-economic indicators on sustainable consumption of domestic electricity in Lithuania," Sustain., vol. 10, no. 2, 2018, doi: 10.3390/su10020162.

11. T. Hong et al., “Commercial Building Energy Saver: An energy retrofit analysis toolkit,” Appl. Energy, vol. 159, pp. 298-309, 2015, doi: 10.1016/j.apenergy.2015.09.002.

12. A. Alajmi, "Energy audit of an educational building in a hot summer climate," Energy Build., vol. 47, pp. 122-130, 2012, doi: 10.1016/j.enbuild.2011.11.033.

13. C. Li, T. Hong, and D. Yan, "An insight into actual energy use and its drivers in high-performance buildings," Appl. Energy, vol. 131, pp. 394-410, 2014, doi: 10.1016/j.apenergy.2014.06.032.

14. S. E. Chidiac, E. J. C. Catania, E. Morofsky, and S. Foo, "Effectiveness of single and multiple energy retrofit measures on the energy consumption of office buildings," Energy, vol. 36, no. 8, pp. 5037-5052, 2011, doi: 10.1016/j.energy.2011.05.050.

M. M. Rahman, M. G. Rasul, and M. M. K. Khan, "Energy conservation measures in an institutional building in sub-tropical climate in Australia," Appl. Energy, vol. 87, no. 10, pp. 2994-3004, 2010, doi: 10.1016/j.apenergy.2010.04.005.

15. J. Kneifel, "Life-cycle carbon and cost analysis of energy efficiency measures in new commercial buildings," Energy Build., vol. 42, no. 3, pp. 333-340, 2010, doi: 10.1016/j.enbuild.2009.09.011.

16. D. Maheswaran, V. Rangaraj, K. K. J. Kailas, and W. A. Kumar, "Energy efficiency in electrical systems," PEDES 2012 IEEE Int. Conf. Power Electron. Drives Energy Syst., 2012, doi: 10.1109/PEDES.2012.6484460.

17. Better Plants, "Energy intensity baselining and tracking guidance," U.S. Dep. Energy, pp. 1689-1699, 2015, [Online]. Available: www.eia.gov/consumption/commercial/terminology.cfm\#P.

18. J. O. E. Koepke, “The Benefits of VFDs on Cooling Towers," HPAC ENGINEERING, 2009. https://www.hpac.com/motorsdrives/article/20928006/the-benefits-of-vfds-on-cooling-towers.

19. Centre for renewable energy Sources, “Energy Audit Guide,” Athens, 2000.

20. R. Walsh, "Conducting effective baseline energy assessments," NQA Global Certification Body, 2018. https://www.nqa.com/en-za/resources/blog/february-2018/effective-baseline-energy-assessment (accessed Jan. 01, 2021). 
